\title{
PREDICTING CRACK SPACING OF REINFORCED CONCRETE TENSION MEMBERS USING STRAIN COMPLIANCE APPROACH WITH DEBONDING
}

\author{
Gintaris KAKLAUSKAS ${ }^{1}{ }^{*} 2^{*}$, Regimantas RAMANAUSKAS(1) ${ }^{1}$, Pui-Lam NG®2 \\ ${ }^{1}$ Department of Reinforced Concrete Structures and Geotechnics, Vilnius Gediminas Technical University, \\ Vilnius, Lithuania \\ ${ }^{2}$ Research Institute of Building and Bridge Structures, Vilnius Gediminas Technical University, Vilnius, Lithuania
}

Received 06 February 2019; accepted 14 March 2019

\begin{abstract}
A novel technique based on strain compliance for investigating the crack spacing of reinforced concrete (RC) tension members has been developed. The new method is based on the mean strain and the partial interaction (stresstransfer) approaches. The strain compliance principle is established by equating together the mean strains of a reinforced concrete block between adjacent primary cracks estimated by the mean strain and the stress-transfer approaches. The distribution of reinforcement strains within the RC block must be known to apply the stress-transfer approach. This technique is intended for the stabilized cracking stage, where formation of new primary cracks has ceased. This work accounts for local effects - fully damaged bond between the concrete and reinforcement near the cracks. Knowledge of a benchmark data point obtained from a reference element is required. The point is defined by the reinforcement ratio, bar diameter and mean crack spacing values. This data point enables the estimation of the mean crack spacing for other RC tension elements. A comparative investigation was carried out, with two different mean strain approaches, following the free-of-shrinkage tension stiffening law and provisions in Eurocode 2. The obtained results provide reasonably accurate estimates of crack spacing compared to experimental values.
\end{abstract}

Keywords: crack spacing, reinforced concrete tension element, mean strain, partial interaction, strain distribution, strain compliance.

\section{Introduction}

Concrete as a structural material has many positive features that have led to the wide adoption of it in constructions throughout the world. Among these are the possibility to form various shapes for architectural purposes, strong in withstanding compressive forces, good resistance to aggressive conditions when compared to steel, and the abundance and the ability to be moulded into different shapes. However, the material has a significant drawback, its ineffectiveness in resisting tensile stresses. Compared to its compressive strength, the tensile strength of concrete is an order of magnitude smaller. When the tensile stresses are excessive, cracks appear in the concrete. The crack width and crack spacing are related to several factors including the bond characteristics between the reinforcement and concrete. Besides, stresses within the concrete redistribute instantly after a crack has been formed and complicate the nonlinear behaviour of concrete.
The assessment of crack width and crack spacing is imperative to the serviceability design of concrete structures. One of the early attempts based on experimental observations by Broms (1965) suggested the crack spacing to be linearly proportional to the concrete cover thickness. Borges (1965), Farra and Jaccoud (1992) proposed empirical formulas and postulated that the crack spacing should be a linear polynomial with the quantities $c$ (concrete cover) and $\phi / \rho_{e f}$ (ratio of bar diameter to effective reinforcement ratio) being the independent variables. Oh and Kang (1987) suggested a semi-empirical equation, where crack spacing has been related to reinforcement axial strain and bar diameter. Lapi, Orlando, and Spinelli (2018) have carried out an exhaustive review on code formulations for cracking in concrete which revealed that various linear functions with $c, s$ (reinforcing bar spacing) and $\phi / \rho_{e f}$ as key independent variables were exceedingly

${ }^{\star}$ Corresponding author. E-mail: gintaris.kaklauskas@vgtu.lt 
dominant in most international codes. The comprehensive review of cracking equations builds on the previous work conducted by Borosnyói and Balázs (2005). Despite the numerous attempts at providing adequate expressions for predicting crack widths and spacing, there remains a considerable lack in understanding and consistency in the approaches. This lack of consistency in models, has driven researches to begin accounting for more complicated phenomena, such as the influence of potential voids in concrete on cracking (Zhang, Yang, \& Gao, 2018) or moving to the inclusion of fracture energy and concrete strength variation in average crack spacing models (Wang, Tao, \& $\mathrm{Nie}, 2017)$. Hence, the discrepancies among the existing formulas and methods, deems further investigation of concrete cracking essential.

This paper aims to address the lack of research into crack spacing modelling techniques that place minimal reliance on empirical variables by presenting an alternative crack modelling philosophy. The authors have established a new approach, taking advantage of both the partial interaction (stress transfer) and mean deformation approaches through compatibility of mean strains. The average deformation behaviour can be established with relatively high accuracy through mean strain methods present in codes, such as Eurocode 2 (Comité Européen de Normalisation [CEN], 2004) or Model Code 2010 (Fédération Internationale du Béton [FIB], 2013), whereas, approaches representing cracks discretely like the stress transfer approach are able to provide the distribution of strains along the RC element. The latter approach provides another significant advantage of accounting for the local effects, such as debonding zones, that directly relate to the reinforcement strains of the investigated element. The presented technique is mechanically sound, transparent and easily adaptable to account for local effects present in reinforced concrete structures. Finally, this research extends the available methods with a novel approach for more robust and consistent evaluation of cracking behaviour, and paves the way for future research on compatibility based crack analysis of flexural and tensile reinforced concrete members that minimises or potentially removes the need for any empiricism.

\section{Crack modelling background}

Initial attempts at developing cracking models were based on a large amount of experimental data, like the work carried out by Gergely and Lutz (1968), who proposed the following best-fit equation based on statistical analysis of contemporary experimental data:

$$
w_{\max }=0.091 \sqrt[3]{t_{b} \cdot A} \cdot r\left(f_{s}-5\right),
$$

where $w_{\max }$ denotes the maximum crack width (mm), $t_{b}$ is the distance from the concrete surface to the centre of the outermost layer of reinforcing bar $(\mathrm{mm}), A$ is the effective concrete area around a single reinforcing bar $\left(\mathrm{mm}^{2}\right), r$ is the ratio of the distance between neutral axis and extreme ten- sion fibre to the distance between neutral axis and reinforcing steel centroid, and $f_{s}$ is the reinforcement stress $(\mathrm{MPa})$.

From the analysis of the published data at the time, Beeby (2004) pointed out that the importance of concrete cover thickness notably outweighs the ratio $\phi / \rho_{e f}$ as a parameter for defining the cracking behaviour. However, no consensus was reached regarding the role of the parameter $\phi / \rho_{e f}$. Some prevailing design code formulations include the factor while others do not.

The factor $\phi / \rho_{e f}$ has its origins from the bond theory. Theoretically, a crack forms when the tensile stress transmitted by reinforcement via bond action to concrete is sufficiently large. At the cracked section, all loading is resisted by the reinforcement and the concrete does not sustain tensile stress. Moving longitudinally away from the cracked section, the bond interaction transfers the stresses from the reinforcement to the intact concrete. This results in decrease of stresses in the reinforcement and corresponding increase in stresses in the concrete as the distance from the crack increases. Such spatial variation of stresses continues until the tensile strength of concrete is reached, where a new crack would then form. The distance required for the development of concrete tensile stress to attain its tensile strength is referred to as the transfer length $l_{t r}$. Equation (2) is derived from the equilibrium condition of the concrete cracking force and force transmitted by bond action (Kaklauskas, Ng, Jakubovskis, \& Ramanauskas, 2016):

$$
A_{c} f_{c t}=n \pi \phi \int_{0}^{l_{t r}} \tau(x) d x,
$$

in which $A_{c}$ is the area of tensile concrete, $f_{c t}$ is the tensile strength of concrete, $n$ is the number of bars, and $\tau(x)$ is the bond stress distribution function.

A new crack can form only at the distance exceeding $l_{t r}$ from an existing crack. If the distance between two cracks is larger than $2 l_{t r}$, the formation of a new intermediate crack is possible. Otherwise, the distance would be insufficient for the development of tensile stresses to be greater than the concrete tensile strength. Hence, the spacing between adjacent cracks $s_{r m}$ falls into the interval between one and two times the transfer length, i.e. $l_{t r} \leq s_{r m} \leq 2 l_{t r}$.

From Eqn (2), the transfer length is affected by the bond stress distribution function $\tau(x)$. In classical approaches (Borges, 1965; Farra \& Jaccoud, 1992), the bond stress has been assumed to be constant, therefore the following expression can be obtained for transfer length by integrating (2):

$$
l_{t r}=\frac{A_{c} f_{c t}}{n \pi \phi \tau_{b}}=\frac{1}{4} \frac{f_{c t}}{\tau_{b, \max }} \frac{\phi}{\rho} .
$$

The crack width $w$ can be evaluated as the difference in displacements between concrete and reinforcement along the crack distance. The displacements can be in turn expressed in terms of the average strain of concrete $\varepsilon_{c m}$ and average strain of reinforcement $\varepsilon_{s m}$ between cracks.

$$
w=s_{r m}\left(\varepsilon_{s m}-\varepsilon_{c m}\right) \text {. }
$$


Other research (Somayaji \& Shah, 1981; Wu \& Zhao, 2012; Eiras-Lopez, Seara-Paz, González-Fonteboa, \& Martinez-Abella, 2017) has shown that the bond stress is varying and governed by a bond-slip function. This affects the solution of (2). Denoting the bond slip by $s$ and the modular ratio of reinforcement to concrete by $\alpha$, the bond stresses and slip are related by the following second-order differential equation. This approach is often described as the stress transfer or the partial interaction approach (Rehm, 1961; Balázs, 1993).

$$
\frac{d^{2} s}{d x^{2}}=\tau \frac{4(1+\alpha \rho)}{E_{s} \phi} .
$$

In general, experimentally obtained bond behaviour of reinforcement can vary with the dimensions of specimen, detailing of reinforcement, and the testing configuration (Balázs, 1993; Torres, Sharaky, Barris, \& Baena, 2016; Carvalho, Miranda, Fernandes, \& Alves, 2018). There is no universally applicable bond-slip law to ensure favourable results of crack analysis for a broad range of geometrical, materials and loading characteristics of RC elements (Rehm, 1961) but only applicable to limited range of RC elements (Jakubovskis, Kaklauskas, Gribniak, Weber, \& Juknys, 2014). A comprehensive investigation on the interface between the reinforcement and concrete carried out by Angst et al. (2017) highlights the importance of understanding the influence of the many time-dependent conditions, such as loading and material ageing on bond behaviour. Empirical coefficients were introduced as an attempt to adjust the crack analysis results (Borosnyói \& Balázs, 2005), as well as bond-slip integration with fracture mechanics through the energy criterion that depended to the reinforcement strains and bar diameter (Bažant \& Oh, 1983; Wang et al., 2017). However, the crack width prediction results were scattered, and the reliability of the analytical results was questionable. An improved technique that combines with advanced measurement methods such as distributed optical fibre sensing to yield better accuracy is desirable (Kaklauskas, Sokolov, Ramanauskas, \& Jakubovskis, 2019).

\section{Core principles and assumptions}

The fundamental basis of the proposed technique involves incorporating two distinct approaches for modelling cracking behaviour of concrete elements into a technique that can provide more accurate mean crack spacing predictions of RC tensile elements. The mean deformation approach provides the advantage of accurate average strain and overall average deformation behaviour estimation of RC elements, whereas its lack of ability to discretely represent cracks and provide strain distributions within the element are compensated by the stress transfer approach, as it provides the needed insight and enables taking of local effects into account.

The integration of these different methods is ensured by an equality condition between the mean strains estimated by both approaches, thus the crack spacing value $s_{r m}$ can be directly obtained from the strain distribution. The base approach without consideration for local effects such as debonding has been shown to be reasonably accurate at predicting crack spacing when the strain distribution profile is assumed as being governed by a linear function (Kaklauskas, Ramanauskas, \& Jakubovskis, 2017). The present study explores the fundamental issue of local effects such as accounting for the extent of debonding zones adjacent to the cracks and implementing the available code for the mean strain estimation.

This work considers the bond in the interface areas close to the normal cracks to be completely deteriorated and therefore lose its ability to transfer any stresses from the reinforcement to the surrounding concrete. The deterioration is mostly considered due to secondary cracking and the mentioned areas are referred to as the debonding zones by the authors. Comparable assumptions can be found in other research (Zhou, Wu, \& Feng, 2017; Maekawa \& Qureshi, 1996). The remaining area between the cracks and these debonding zones is defined as the effective zone, where partial interaction is in effect and thus the distribution of strains can be described by a shape function. A linear function has been implemented to describe the strain distribution in the effective zone, as in Kaklauskas et al. (2017). Such a linear expression has been previously suggested by Marti, Alvarez, Kaufmann, and Sigrist (1998) and Murray, Gilbert, and Castel (2018). These concepts are illustrated in Figure 1 for a concrete block, which is of length equivalent to the distance between two normal cracks.

The current study assumes constant reinforcement strain in the debonding zones, as can be seen in Figure 1, and equal to the reinforcement strain within the crack. As the ability for concrete to transfer stresses in a cracked section (tension softening) is neglected, concrete strains are equal to zero in the same zones. To establish the average crack spacing value of a considered element, a quantitative expression for the length of the debonding zone

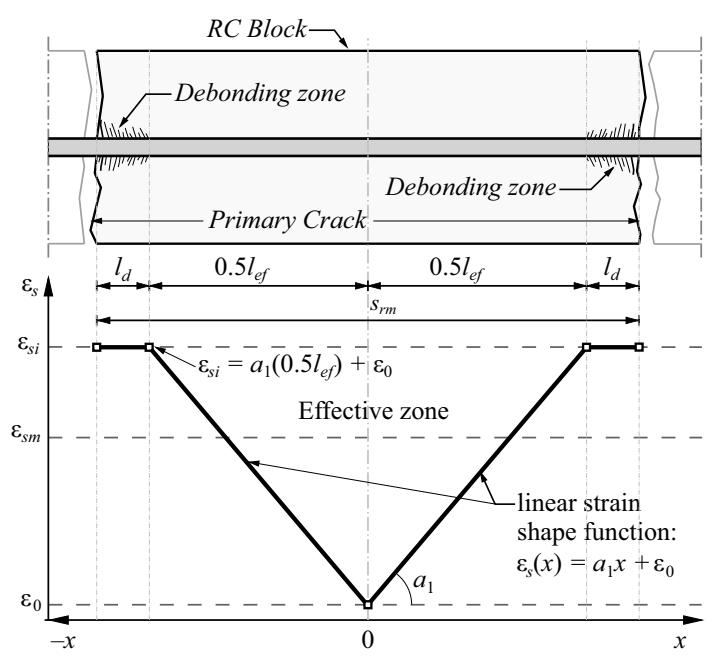

Figure 1. Reinforcement strains represented by the debonding zones and effective zone 
is required. Experimental results of reinforced concrete tension elements by Houde (1974) were taken as the initial base for the derivation of the debonding zone length model.

A simplified approximation is adopted using a linear shape function over the obtained data points. The experimental strains are provided in Figure 2(a), that were smoothed out by averaging both sides and then approximated with a linear function over various loading levels as can be seen in Figure 2(b). The point where the approximated line meets the maximum corresponding reinforcement strain value is considered the end of the debonding zone; hence the remaining distance between the crack and this point is considered the length of the debonding zone. Plotting the approximation at various loading levels provides an evolution of the length of the debonding zone with respect to the maximum reinforcement strain value (Figure 2(b)). The linear function superimposed on the original unsmoothed data results is shown in Figure 2(c).

The chosen simplification of a linear shape function is adopted only to illustrate the core concepts presented in this paper and remain to be a subject for further investigation. The linear approximation is clearly more accurate for higher loading levels, as shown in Figures 2(b)-2(c), and less so for the very small loading levels (Kaklauskas, 2017). The authors consider this acceptable as the aim of this paper is to better understand the cracking behaviour of RC tension members, hence only higher loading levels corresponding to the stabilized cracking stage are of key interest. Additional data was obtained from publications by Houde (1974) and Kankam (1997) for which identical approximations were carried out as described above. The obtained results, depicting the length of the debonding zone normalized by the reinforcement bar diameter against the reinforcement stresses in the cracked section, are presented in Figure 3. Though the data in Figure 3 demonstrates certain degree of scatter, it provides a basis to relate the debonding zone length with the reinforcement stress, and thus to conceptualise the crack spacing model. For the purpose of devising a more reliable expression for debonding zone length, additional data should be analysed.

The debonding zone length $l_{d}$ has been linearly related to the reinforcement stress $\sigma_{s}$, and expressed through the reinforcement strains, the suggested expression is provided as:

$$
l_{d}=0.00167 \sigma_{s} \phi \cong 1000 \varepsilon_{s} \phi / 3 .
$$

The authors would like to remark that the original linear regression would numerically give rise to small values of intercepts at the coordinate axes, shown in Figure 3 as a dashed line. As the offset of regression line from the origin is very minor, the regression has been repeated with the assumption of zero intercepts at the coordinate axes, as shown in Figure 3 as a solid line. The stresses in expression (6) should be provided in MPa.

As conceptually shown in Figure 1, the shape function for the effective zone contains two key parameters, the gradient $a_{1}$ and the constant $\varepsilon_{0}$, representing the minimum reinforcement strain value present at the middle of the investigated RC block. Another important feature of the proposed technique is the reliance on only a single predetermined data point, defined by the reference average crack spacing, reinforcement ratio and bar diameter values of a RC tension member. These reference values are taken as the starting point for benchmarking calculations, from which crack spacing values are estimated for other elements. The elements in question can be of different reinforcement bar sizes and different reinforcement ratio. These variables can be either established experimentally or estimated by numerical means. In this paper, experimental data were collected, and the reference RC element was taken as having a $14 \mathrm{~mm}$ diameter bar, $100 \times 100 \mathrm{~mm}$ section (indicating a reinforcement ratio of $1.54 \%$ ), and the determined mean crack spacing value of $162 \mathrm{~mm}$ as discussed further in this work.
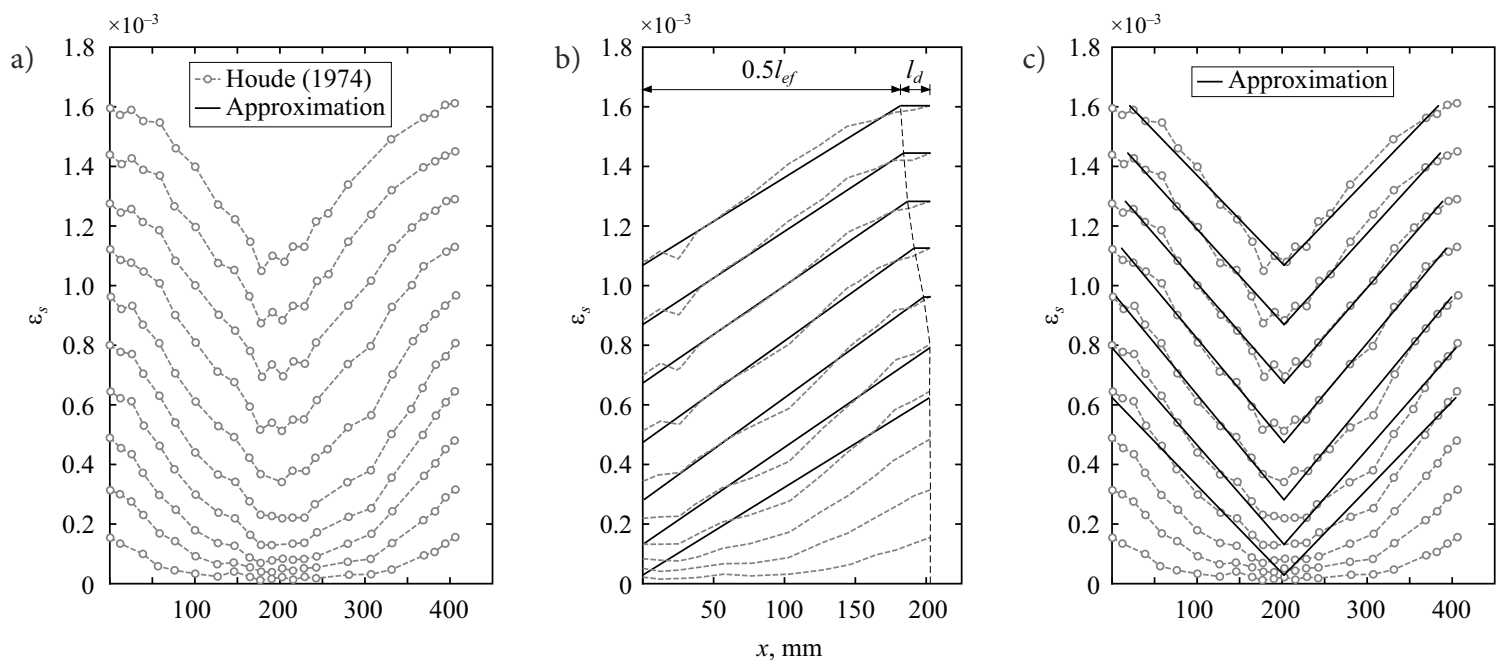

Figure 2. (a) Experimental strain profiles by Houde (1974); (b) Approximation of reinforcement strain profile with a linear shape function; (c) Linear approximation superimposed over the original data 


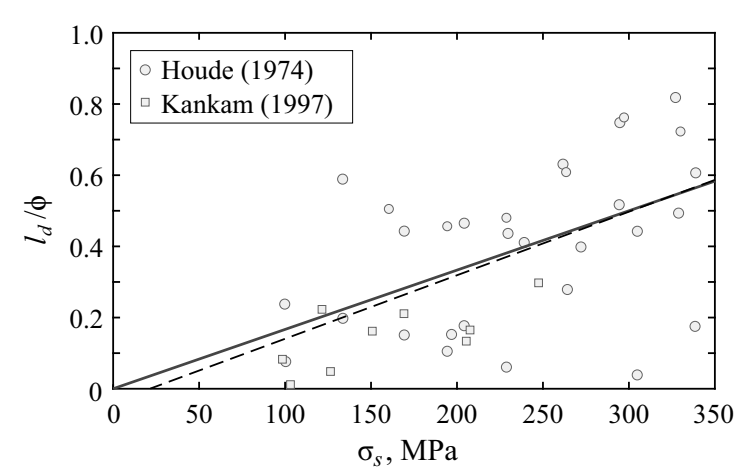

Figure 3. Debonding zone length normalized over reinforcement diameter against experimental strains in the reinforcement reported by Houde (1974) and Kankam (1997)

The discussed principles that form the foundation of the proposed technique as well as the leading assumptions can be briefly summarized as follows:

- The stabilized cracking stage is considered, hence new primary cracks do not appear, and only crack widths continue to grow with increased strains;

- The average deformation behaviour of an element can be evaluated from a RC segment with an equivalent length to the distance between two primary cracks;

- A linear function governs the reinforcement strains within the effective zone, where interaction between concrete and reinforcement is still present due to bond that is intact;

- All elements can be described by a universal bondslip relationship, independent from reinforcement ratio or bar diameter;

- Tension softening effect is neglected, concrete does not transfer any stresses in the crack;

- Bond between the concrete and reinforcement is considered negligible within a certain length of debonding zone from the crack opening, no bond stresses are therefore present along the debonding zone and the reinforcement strains remain constant.

\section{Crack spacing estimation technique}

The method relies on carrying out calculation with reference to a single known data point, representing the reference value of mean crack spacing that is established a priori either experimentally or numerically for a RC tension element of given designated reinforcement ratio and reinforcement diameter. The average reinforcement strain $\varepsilon_{s m}$ is calculated for this member by any mean deformation method (such as Eurocode 2 (CEN, 2004)) for a given load $P_{i}$. Kaklauskas et al. (2017) used a tension stiffening model (Kaklauskas, Tamulenas, Gribniak, Ng, \& Kupliauskas, 2015) to evaluate the crack spacing. In this paper, results are presented for both cases of Eurocode 2 (CEN, 2004) and the tension stiffening model cases with due consideration of the considered local effects - debonding zones.
After obtaining the mean reinforcement strain value, the concepts of effective and debonding zones are applied to the stress transfer approach. The former is expressed by a linear equation, whereas the latter is estimated directly according to the extent of the debonding zone. With these zones established, the mean reinforcement strain of the stress transfer approach is expressed and the coefficients $\varepsilon_{0}$ and $a_{1}$ can be determined.

By establishing the bond stress value for the reference element and following the assumption of the universal bond-slip relationship for all investigated elements, the shape function coefficients can be evaluated. Due to the linear shape function, the bond will be constant as in the classical bond theory. The average distance between cracks can then be determined from the strain distribution of the stress transfer approach by ensuring compatibility of the mean deformation and the partial interaction methods through the equality of mean reinforcement strain, which is referred to as the strain compliance approach. Depending on the adopted way of implementing the average deformation method it can either be done numerically or analytically. For the case of using Eurocode 2 (CEN, 2004 ) as the selected mean deformation method, the procedure is summarized in Figure 4 with a flowchart where key equations are shown as well.

Following the flowchart, $\rho, \phi, s_{r m}$ and load $P_{i}$ values of the reference element are determined. The next step involves defining the strain function of the effective zone in terms of maximum reinforcement strains and function coefficients, establishing the length of the debonding zone from the pre-established model and estimating the mean crack spacing value in accordance with Eurocode 2 (CEN, 2004). All equations and values from this step are then combined into a system of equations, representing the strain compliance concept, equality of mean strain and partial interaction approaches. Solving the system of equations provides the required strain value at the middle of the RC segment and the slope coefficient al which in turn enables the estimation of the bond stress. All the equations are given for one half of the RC block under investigation, from the middle between two consecutive cracks to the location of the normal crack. The obtained bond stress value and minimum strain value are then used to estimate the crack spacing of any other RC tension element. Reinforcement ratio $\rho$ and diameter $\phi$ of the chosen RC element are selected. Equating bond stress $\tau$ to the previous equation provides the al coefficient. An iterative procedure is then implemented to find the required reinforcement strain value at the cracked section to meet the strain compliance criteria, i.e. equality of mean strains obtained from the average deformation approach and the stress transfer approach. When mean strain values converge, a solution is found and the average crack spacing value from the effective zone shape function and debonding zone length formulas can be established. 

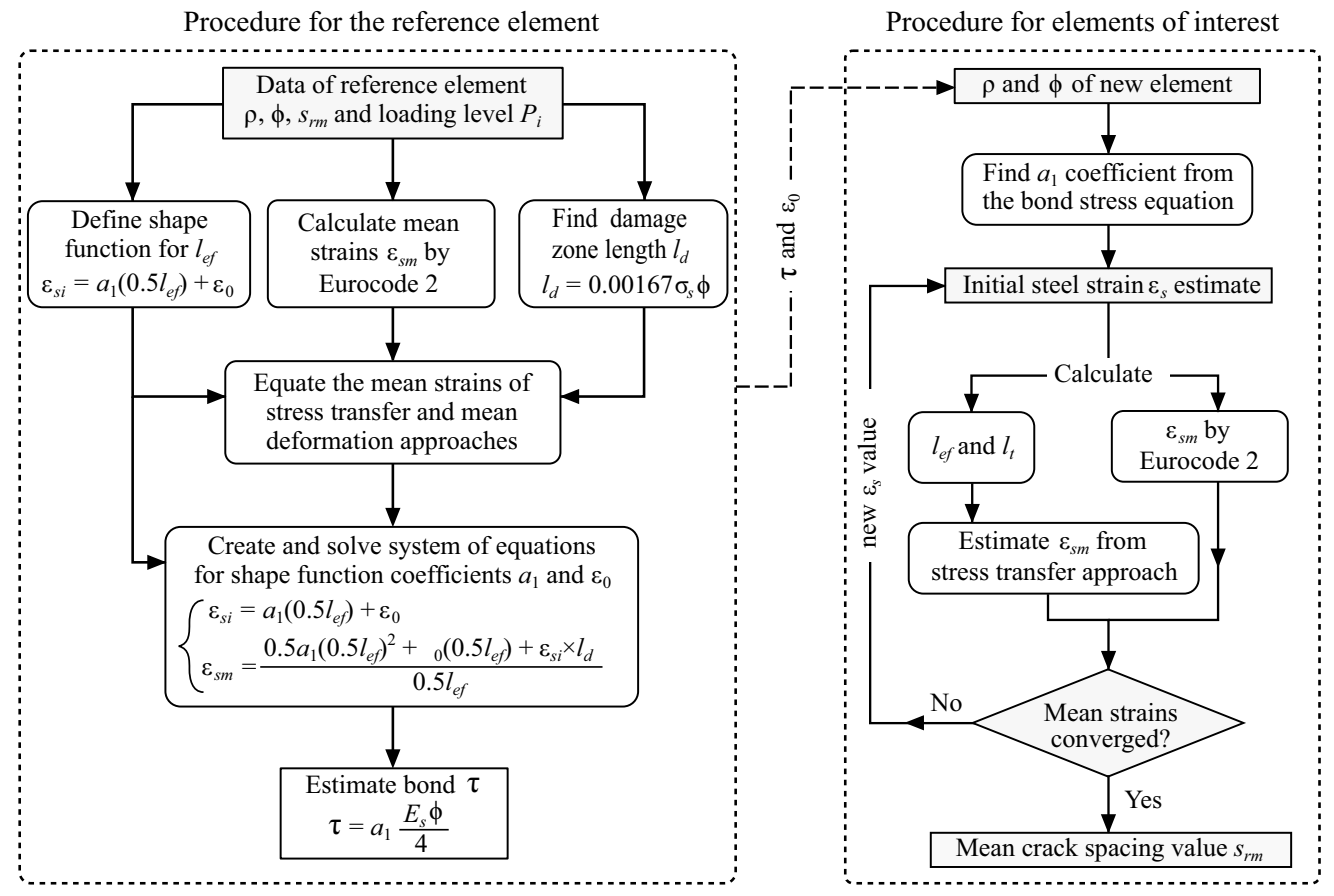

Figure 4. Flowchart of the proposed crack spacing prediction technique with debonding included

\section{Comparison of predicted and experimental crack spacing results}

In order to investigate the prospects of this method, experimental data was necessary of concrete element crack spacing values to act as the reference data described in the previous section. A collection of experimental data from multiple sources, as detailed by Kaklauskas et al. $(2017,2018)$, was employed for this purpose. The data comprised of a total of 173 specimen results, representing crack spacing values for $100 \times 100 \mathrm{~mm}$ section reinforced concrete elements and reinforcement bar diameters ranging from $10 \mathrm{~mm}$ to $20 \mathrm{~mm}$. For the section geometry in question, bar diameters represented reinforcement ratio values of $0.79 \%, 1.13 \%, 1.54 \%, 2.01 \%$ and $3.14 \%$, that cover the most commonly used configuration expected in actual reinforced concrete structural elements. Exact specimen counts for each case are given in Table 1. The proposed method necessitates a single data point defined by a crack spacing value and a reinforced concrete ratio. The authors selected the specimens reinforced with a 14 $\mathrm{mm}$ steel bar (reinforcement ratio of $1.54 \%$ ) as the reference data, whereas the remaining data will be used for a comparative validation. The average crack spacing for the chosen case is $161.2 \mathrm{~mm}$. Concrete compressive strength was taken as $40 \mathrm{MPa}$ and tensile strength as $2.9 \mathrm{MPa}$. Elasticity modulus for steel reinforcement and concrete were taken as $200 \mathrm{GPa}$ and $30 \mathrm{GPa}$, respectively. It was shown that compressive strength has only a marginal effect on the crack spacing (Kaklauskas et al., 2017). The loading level for the reference element was taken as equivalent to 300 $\mathrm{MPa}$ induced stress in the reinforcement in the crack. Following the procedure detailed the previous section, crack spacing values were obtained from the strain distribution, an example of the strain profiles and their variation depending on different bar diameter and reinforcement ratio is given in Figure 5. The key results are summarised in Table 1 where they are compared with the experimental data and the values estimated per Eurocode 2 (CEN, 2004) and Model Code 2010 (FIB, 2013). A tension stiffening model was proposed by Kaklauskas et al. (2015) as an alternative of the Eurocode 2 provisions for mean strain calculations, and the corresponding crack spacing calculation results are included in Table 1. Additionally, a simplified crack spacing equation is provided in expression (7), whose calculation results are given in the last column of Table 1 for comparison. From the presented data in Table 1, it is observed that Eurocode 2 (CEN, 2004) provides the largest crack spacing results, and the crack spacing values computed from all other methods are ranging between $60 \%$ and $86 \%$ of the Eurocode 2 (CEN, 2004) predictions.

The authors found the results to be considerably accurate in comparison with the experimental results. Furthermore, the tension stiffening relationship that was used in research by Kaklauskas et al. (2017), displayed better performance than Model Code 2010 (FIB, 2013) and Eurocode 2 (CEN, 2004) predictions. The proposed technique successfully demonstrates the validity of fundamental concepts such as the use of a RC block defined by two consecutive cracks to be representative of the mean deformation behaviour of a full-length concrete specimen in the stabilized cracking stage. The authors believe that the strain compliance technique enables new possibilities in exploring cracking and deformation behaviour of RC tensile elements. The flexibility to use any mean strainbased approach for estimating the average reinforcement strains is worth exploring in the future. 
Table 1. Comparison of crack spacing values

\begin{tabular}{|c|c|c|c|c|c|c|c|c|}
\hline \multirow{2}{*}{$\begin{array}{c}\phi \\
(\mathrm{mm})\end{array}$} & \multirow{2}{*}{$\begin{array}{c}\rho \\
(\%)\end{array}$} & \multirow{2}{*}{$\begin{array}{c}\text { No. of } \\
\text { specimens }\end{array}$} & \multicolumn{6}{|c|}{$s_{r m}(\mathrm{~mm})$} \\
\hline & & & Experiment & $\begin{array}{c}\text { Eurocode } 2 \\
(\mathrm{CEN}, 2004)\end{array}$ & $\begin{array}{l}\text { Model Code } 2010 \\
\quad(\text { FIB, 2013) }\end{array}$ & $\begin{array}{l}\text { Proposed } \\
\text { model }\end{array}$ & $\begin{array}{l}\text { With tension stiffening model } \\
\text { (Kaklauskas et al., 2015) }\end{array}$ & $\begin{array}{l}\text { Expression } \\
\quad(7)\end{array}$ \\
\hline 10 & 0.79 & 49 & 216 & 347 & 298 & 211 & 226 & 219 \\
\hline 12 & 1.13 & 11 & 183 & 300 & 255 & 181 & 188 & 186 \\
\hline 14 & 1.54 & 45 & 161 & 268 & 226 & 161 & 161 & 162 \\
\hline 16 & 2.01 & 20 & 150 & 244 & 204 & 148 & 143 & 144 \\
\hline 20 & 3.14 & 48 & 138 & 207 & 171 & 133 & 115 & 120 \\
\hline
\end{tabular}

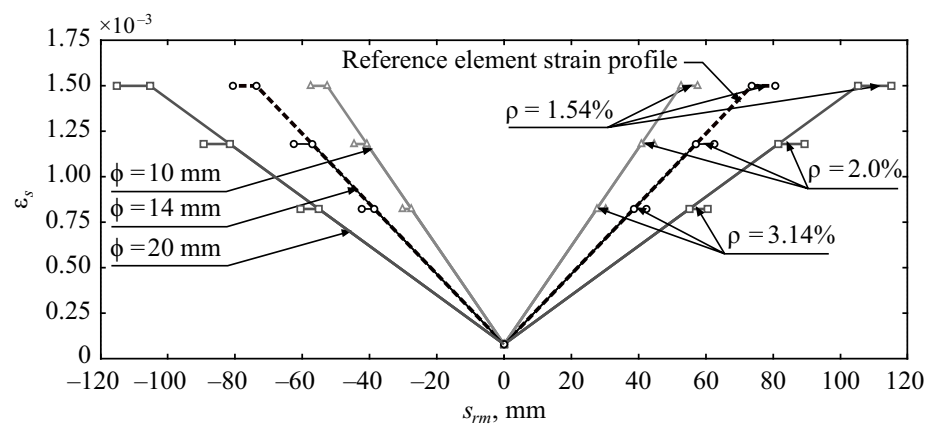

Figure 5. Reinforcement strain distributions over the length between consecutive cracks

In addition to the presented results in Table 1, the procedure has been carried out for a series of various reinforcement ratio and bar diameter values, with the values ranging from 0.78 to $4.0 \%$ for the former and $10-25 \mathrm{~mm}$ for the latter variable. The obtained mean crack spacing data has been regressed in terms of $\phi / \rho$ parameter to provide the following expression, as a demonstration of the model derivation capabilities of the suggested technique:

$$
s_{r m}=0.021+0.155(\phi / \rho)
$$

where bar diameter $\phi$ and $s_{r m}$ must be expressed in metre and reinforcement ratio $\rho$ expressed in a decimal fraction. In practical structural design, expression (7) may be taken as an approximate prediction of the mean crack spacing. For ease of comparison, the crack spacing values calculated with (7) are listed in the last column of Table 1. It is important to note that, whereas the presented mean crack spacing expression is empirical in nature, the underlying technique suggested in this paper is an integration of the theoretical framework with nominal empirical factors.

\section{Conclusions}

This paper has presented a fresh perspective on modelling crack spacing by employing a method, that is based on a combination of the mean strain and stress transfer approaches, with the consideration for local effects, viz. the debonding phenomenon between concrete and reinforcement. The approach is intended for tensile reinforced concrete (RC) elements, which can be generalized to encompass the tensile mechanical behaviour of RC. Fundamental concepts have been incorporated in the approach, including the effective and debonding zones that define the reinforcement strain distribution within an investigated element. The average strain value over its distribution profile along the reinforcement, representing the average strain of the stress transfer approach, is equated to the strains predicted by a mean deformation-based approach. This equality, referred to as the strain compliance principle, enables the estimation of the distance between cracks from the reinforcement strain distribution. Extension of the present study to encompass crack width estimation is recommended for future research. The following points summarize the key conclusions from this research:

- The technique is mechanically sound with minimal dependence on experimentally or numerically obtainable variables in the form of the mean crack spacing of the designated reference RC tension member;

- The strain compliance approach, that equates average strain of the mean deformation and partial interaction approaches, is a new technique for investigating concrete cracking and deformation behaviour of RC tension elements;

- The technique is adaptable and flexible to incorporate the concept of debonding zone to reflect local effects near the cracks, where concrete bond with the embedded reinforcement is largely deteriorated. The consideration of debonding phenomenon has improved the accuracy of crack spacing model;

- Predicted crack spacing values were found to be very close to the experimental results collected from multiple sources. Compared to Model Code 2010 (FIB, 2013) or Eurocode 2 (CEN, 2004) estimations, the results are more consistent;

- More in-depth studies are recommended in the future to determine the limits and possibilities of the 
strain compliance technique to predict crack spacing of RC tension members through other shape functions, further research on local effects and bond formulations is also advisable to provide more solid results to verify the technique.

\section{Acknowledgements}

The authors gratefully acknowledge the financial support provided by the European Social Fund according to the activity "Improvement of researchers" qualification by implementing world-class $\mathrm{R} \& \mathrm{D}$ projects' of Measure No. 09.3.3-LMT-K-712 (Project. No. 09.3.3-LMTK-712-01-0145) for prof. Gintaris Kaklauskas and the European Commission Research Executive Agency under the Marie Skłodowska-Curie Actions (Grant No. 751461) for dr. Pui-Lam Ng.

\section{Funding}

This work was supported by the European Social Fund according to the activity "Improvement of researchers" qualification by implementing world-class $R \& D$ projects' of Measure No. 09.3.3-LMT-K-712 (Project. No. 09.3.3-LMT-K-712-01-0145); European Commission Research Executive Agency under the Marie SkłodowskaCurie Actions (Grant No. 751461).

\section{Author contributions}

Gintaris Kaklauskas conceived the study, Gintaris Kaklauskas and Regimantas Ramanauskas are responsible for the design and development of the data analysis, Regimantas Ramanauskas and Pui-Lam Ng were responsible for data collection and analysis. Gintaris Kaklauskas was responsible for data interpretation. Regimantas Ramanauskas and Pui-Lam Ng were responsible for writing of the draft, Gintaris Kaklauskas was responsible for draft review and corrections, Gintaris Kaklauskas was responsible for research management.

\section{Disclosure statement}

The authors declare no conflict of interest.

\section{References}

Angst, U. M., Geiker, M. R., Michel, A., Gehlen, C., Wong, H., Isgor, O. B., Elsener, B., Hansson, C. M., François, R., Hornbostel, K., Polder, R., Alonso, M. C., Sanchez, M., Correia, M. J., Criado, M., Sagüés, A., \& Buenfeld, N. (2017). The steel-concrete interface. Materials and Structures, 50(2), 143. https://doi.org/10.1617/s11527-017-1010-1

Balázs, G. L. (1993). Cracking analysis based on slip and bond stresses. ACI Materials Journal, 90, 340-340.

Bažant, Z. P., \& Oh, B. H. (1983). Spacing of cracks in reinforced concrete. Journal of Structural Engineering, 109(9), 2066-2085. https://doi.org/10.1061/(ASCE)0733-9445(1983)109:9(2066)

Beeby, A. W. (2004). The influence of the parameter $\phi / \rho_{\text {eff }}$ on crack widths. Structural Concrete, 5(2), 71-83.

https://doi.org/10.1680/stco.2004.5.2.71
Borges, J. F. (1965). Cracking and deformability of reinforced concrete beams. Laboratório Nacional de Engenharia Civil.

Borosnyói, A., \& Balázs, G. L. (2005). Models for flexural cracking in concrete: the state of the art. Structural Concrete, 6(2), 53-62. https://doi.org/10.1680/stco.2005.6.2.53

Broms, B. B. (1965, October). Crack width and crack spacing in reinforced concrete members. ACI Journal Proceedings, 62(10), 1237-1256.

Carvalho, E. P., Miranda, M. P., Fernandes, D. S., \& Alves, G. V. (2018). Comparison of test methodologies to evaluate steelconcrete bond strength of thin reinforcing bar. Construction and Building Materials, 183, 243-252.

https://doi.org/10.1016/j.conbuildmat.2018.06.109

Comité Européen de Normalisation. (2004). Eurocode 2: Design of concrete structures - Part 1-1: General rules and rules for buildings. Brussels, Belgium.

Eiras-Lopez, J., Seara-Paz, S., González-Fonteboa, B., \& Martinez-Abella, F. (2017). Bond behavior of recycled concrete: analysis and prediction of bond stress-slip curve. Journal of Materials in Civil Engineering, 29(10), 04017156.

https://doi.org/10.1061/(ASCE)MT.1943-5533.0002000

Farra, B., \& Jaccoud, J. P. (1992, October). Bond behaviour, tension stiffening and crack prediction of high strength concrete. Paper presented at Proceedings of the International Conference of Bond in Concrete, Riga, Latvia.

Fédération Internationale du Béton. (2013). fib model code for concrete structures 2010. Ernst \& Sohn.

https://doi.org/10.1002/9783433604090

Gergely, P., \& Lutz, L. A. (1968). Maximum crack width in reinforced concrete flexural members. ACI Special Publication, 20, 87-117.

Houde, J. (1974). Study of force-displacement relationships for the finite-element analysis of reinforced concrete $(\mathrm{PhD}$ thesis, McGill University). Montreal, Canada.

Jakubovskis, R., Kaklauskas, G., Gribniak, V., Weber, A., \& Juknys, M. (2014). Serviceability analysis of concrete beams with different arrangements of GFRP bars in the tensile zone. Journal of Composites for Construction, 18(5), 04014005. https://doi.org/10.1061/(ASCE)CC.1943-5614.0000465

Kaklauskas, G. (2017). Crack model for RC members based on compatibility of stress-transfer and mean strain approaches. Journal of Structural Engineering, 143(9), 04017105. https://doi.org/10.1061/(ASCE)ST.1943-541X.0001842

Kaklauskas, G., Tamulenas, V., Gribniak, V., Ng, P. L., \& Kupliauskas, R. (2015, January). Tension-stiffening behaviour of reinforced concrete ties of various strength classes. In International Conference on Performance-based and Life-cycle Structural Engineering (pp. 582-590). School of Civil Engineering, The University of Queensland. https://doi.org/10.14264/uql.2016.1174

Kaklauskas, G., Ng, P. L., Jakubovskis, R., \& Ramanauskas, R. (2016). Numerical modelling of cracked RC tension members using stress-transfer approach. In Mechanics of Structures and Materials XXIV (pp. 166-171). CRC Press.

Kaklauskas, G., Ramanauskas, R., \& Jakubovskis, R. (2017). Mean crack spacing modelling for RC tension elements. Engineering Structures, 150, 843-851. https://doi.org/10.1016/j.engstruct.2017.07.090

Kaklauskas, G., Tamulenas, V., Bado, M. F., \& Bacinskas, D. (2018). Shrinkage-free tension stiffening law for various concrete grades. Construction and Building Materials, 189, 736744. https://doi.org/10.1016/j.conbuildmat.2018.08.212 
Kaklauskas, G., Sokolov, A., Ramanauskas, R., \& Jakubovskis, R. (2019). Reinforcement strains in reinforced concrete tensile members recorded by strain gauges and FBG sensors: experimental and numerical analysis. Sensors, 19(1), 200. https://doi.org/10.3390/s19010200

Kankam, C. K. (1997). Relationship of bond stress, steel stress, and slip in reinforced concrete. Journal of Structural Engineering, 123(1), 79-85. https://doi.org/10.1061/(ASCE)0733-9445(1997)123:1(79)

Lapi, M., Orlando, M., \& Spinelli, P. (2018). A review of literature and code formulations for cracking in R/C members. Structural Concrete, 19(5), 1481-1503. https://doi.org/10.1002/suco.201700248

Marti, P., Alvarez, M., Kaufmann, W., \& Sigrist, V. (1998). Tension chord model for structural concrete. Structural Engineering International, 8(4), 287-298. https://doi.org/10.2749/101686698780488875

Murray, A., Gilbert, R. I., \& Castel, A. (2018). Spacing of cracks in reinforced concrete based on a variable transfer length model. Journal of Structural Engineering, 144(7), 04018090. https://doi.org/10.1061/(ASCE)ST.1943-541X.0002095

Oh, B. H., \& Kang, Y. J. (1987). New formulas for maximum crack width and crack spacing in reinforced concrete flexural members. ACI Structural Journal, 84(2), 103-112.

Maekawa, K., \& Qureshi, J. (1996). Computational model for reinforcing bar embedded in concrete under combined axial pullout and transverse displacement. Doboku Gakkai Ronbunshu, 538, 227-239. https://doi.org/10.2208/jscej.1996.538_227

Rehm, G. (1961). Ueber die Grundlagen des Verbundes zwischen Stahl und Beton. Deutscher Ausschuß für Stahlbeton (DAfStb), 138 .
Somayaji, S., \& Shah, S. P. (1981, May). Bond stress versus slip relationship and cracking response of tension members. ACI Journal Proceedings, 78(3), 217-225.

Torres, L., Sharaky, I. A., Barris, C., \& Baena, M. (2016). Experimental study of the influence of adhesive properties and bond length on the bond behaviour of NSM FRP bars in concrete. Journal of Civil Engineering and Management, 22(6), 808-817. https://doi.org/10.3846/13923730.2014.914097

Wang, J. J., Tao, M. X., \& Nie, X. (2017). Fracture energy-based model for average crack spacing of reinforced concrete considering size effect and concrete strength variation. Construction and Building Materials, 148, 398-410. https://doi.org/10.1016/j.conbuildmat.2017.05.082

Wu, Y. F., \& Zhao, X. M. (2012). Unified bond stress-slip model for reinforced concrete. Journal of Structural Engineering, 139(11), 1951-1962. https://doi.org/10.1061/(ASCE)ST.1943-541X.0000747

Zhang, C. C., Yang, X. H., \& Gao, H. (2018). Air-void-affected zone in concrete beam under four-point bending fracture. Journal of Civil Engineering and Management, 24(2), 130-137. https://doi.org/10.3846/jcem.2018.456

Zhou, B., Wu, R., \& Feng, J. (2017). Two models for evaluating the bond behavior in pre-and post-yield phases of reinforced concrete. Construction and Building Materials, 147, 847-857. https://doi.org/10.1016/j.conbuildmat.2017.04.067 